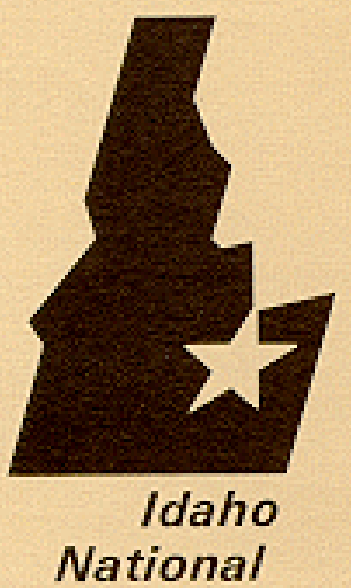

Engineering

Laboratory

Managed

by the U.S.

Department

of Energy
EGG-WTD-10256

May 1992

Rapid Assay of Plutonium in Soils by Passive L X-Ray Counting

\author{
R. J. Gehrke \\ M. H. Putnam \\ S. G. Goodwin \\ R. L. Kynaston
}

Received by OSTI

JUL 231992

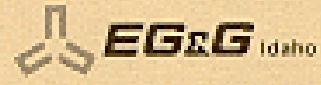

Wark portomed undor

Dof Contract

Na DE-ACO7-761COISTO
COVER 
This document contains new concepts or the author(s) interpretation of new calculations and/or measurements; accordingly, EG\&G Idaho, Inc. is required by the United States Government to include the following disclaimer:

\section{DISCLAIMER}

This report was prepared as an account of work sponsored by an agency of the United States Grvernment. Neither the United States Government nor any agency thereof, nor arry of their employees, makes any warranty, express of impliod, of assumes any legal fabilty or responsibility for the accuracy, completeness, of useluluess of any information, apparatus, product or process dsclosed, or represents that its use would not infringe privately owned nights. Feforences herein to any specific commercial product, process, or service by trade name, trademark. manulacturer, of otherwise, does not necessarily constitule or imply is endorsement, recommendation, or favoring $\mathrm{b} y$ the United States Government or any nocessarily state or refort those and opinions of authors expressed herein do not thereot. 


\title{
Rapid Assay of Plutonium in Soils by Passive L X-Ray Counting
}

\author{
R. J. Gehrke \\ M. H. Putnam \\ S. G. Goodwin \\ R. L. Kynaston
}

Published May 1992

\section{Idaho National Engineering Laboratory EG\&G Idaho, Inc. Idaho Falls, Idaho 83415}


Rapid Assay of Plutonium in Soils by Passive L X-Ray Counting EGG-WTD-10256

Prepared by:

$\frac{\text { Posit fol like }}{\text { R. J. Gen re }} \frac{5 / 14 / 92}{\text { Date }}$

Tiara Af. Antrum

M. H. Putnam

Scr th M. Mordvin per telecion

Ron Kymaton per telecon RI A

$\frac{5 / 14 / 4,3}{\text { Date }}$

$\frac{5 / 14 / 92}{\text { Date }}$

Approved by:

ow ah

D. W. Avers
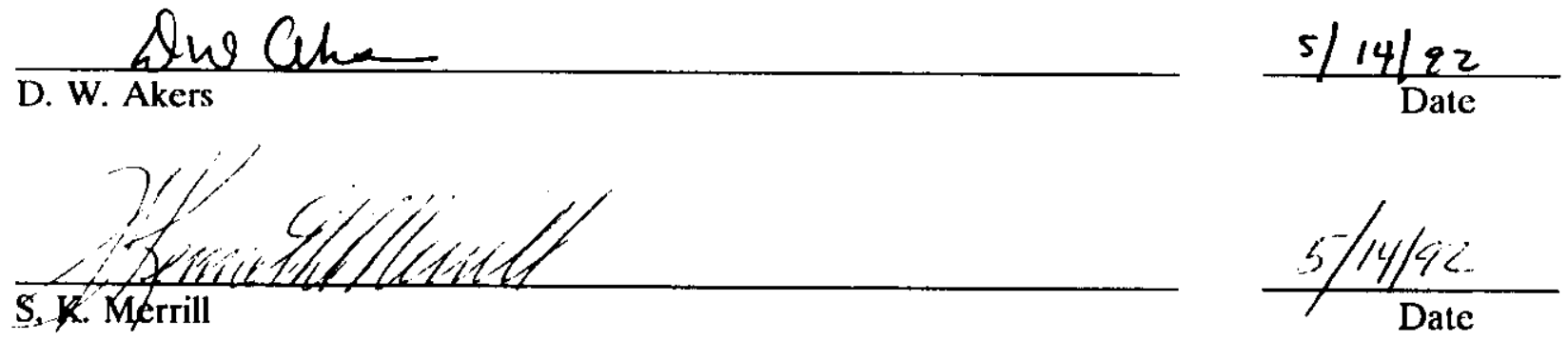

S. R. Merrill

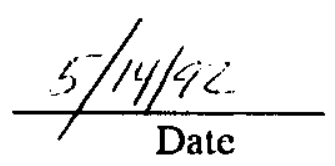

Technical Review by:

R. H. Delmer

R. G. Helmer

$$
\frac{5 / 14 / 92}{\text { Date }}
$$




\section{This Page Intentionally Left Blank}




\begin{abstract}
A technique has been developed to rapidly measure the presence of plutonium in soils, filters, smears, and glass waste forms by measuring the uranium L-shell $x$-ray emissions associated with the decay of plutonium. In addition, the technique can simultaneously acquire spectra of samples and automatically analyze them for the amount of americium, and gamma-ray emitting activation and fission products present. The samples are counted with a large area, thin-window, $n$ type Ge spectrometer which is equally efficient for the detection of low energy $\mathrm{x}$-rays $(>10 \mathrm{keV})$, as well as high-energy gamma rays $(>1 \mathrm{MeV})$. A 8192-channel analyzer is used to acquire the entire photon spectrum at one time. A dual-energy, time-tagged pulser, that is injected into the test input of the preamplifier to monitor the energy scalc, detector resolution, and pulse pile-up will be installed in FY-92. The $\mathrm{L} x$-ray portion of each spectrum is analyzed by a linear least-squares spectral litting technique originally developed for the analysis of spectra from NaI(TI) detectors. The gamma-ray portion of each spectrum is analyzed by a standard Ge gamma-ray analysis package. Detection limits (also referred to as lower limits of detection) for plutonium in contaminated soils that have been achieved by this technique are reported.
\end{abstract}




\section{This Page Intentionally Left Blank}




\section{SUMMARY}

This report presents an analysis technique for measuring the presence of plutonium in soils, smears, and filters by counting uranium $\mathrm{L} x$-rays produced by the alpha decay of plutonium radioisotopes (usually ${ }^{239} \mathrm{Pu}$ ). The technique involves accumulating both the $x$-ray and gamma-ray spectrum in one count so that the spectrometer can simultaneously monitor for gamma and alpha cmitting radionuclides. Application of this device with a sample holder will ultimatcly allow rapid and automated measurement of a hundred samples per day in a field-deployable environment. The ficlddeployable unit will be housed in a mobile trailer used for evaluating the status of contamination spread during buried transuranic waste retrieval.

Efforts to develop rapid assay of plutonium in soil by $\mathrm{L}$ x-ray counting techniques are being pursued at the Idaho National Engineering Laboratory (INEL). These efforts are intended to bring this analysis technique into routine use by employing equipment and instrumentation that is or will soon be commercially available and by developing automated calibration, counting, and analysis techniques.

Since the earlier study of $\mathrm{Pu}$ assay by measurement of the $\mathrm{U} \mathrm{L} x$-rays by Trujillo et al. was reported in 1980, several advances have occurred in high-purity spectrometry:

- Detector crystals are now routinely produced with crystal diameters of $\geq 60 \mathrm{~mm}$; pulscheight analyzers with 8192 and 16384 channels and excellent pulse-height linerity are commercially available.

- Highly precise monitoring of the spectrometer is now possible with advanced pulser technology.

- High-speed, low-cost laboratory and personal computers with megabyte-size memorics and hard disks are in common use.

The current study takes advantage of these advances to result in an analysis system that can be operated automatically $24 \mathrm{~h} /$ day with a sample changer in a laboratory or mobile trailer with $110-\mathrm{V}$ AC power.

Soil samples, sufficiently homogeneous for the current counting technique, are prepared by sicving and/or milling dry soil to reduce the maximum particulate size to less than -200 mesh. In the current study, sample containers were used that are a few millimeters larger in diameter than the detector crystal and are only a few millimeters thick. A typical sample container is $\sim 65 \mathrm{~mm}$ in diameter $x-3 \mathrm{~mm}$ in thickness and holds 10 to $15 \mathrm{~g}$ of soil.

The detector consists of a large ( $\sim 60 \mathrm{~mm}$ in diameter), thin-window, coaxial-type germanium detector capable of efficiently measuring photons with encrgies ranging from $\sim 10$ to $\sim 2000 \mathrm{kcV}$. This type of detector not only allows measurement of plutonium activity via the $\mathrm{L} x$-rays but also has the ability to detect other gamma rays emitting radionuclides.

The spectrometer is being equipped with a dual-energy pulser that is injected into the test input of a resistive feedback pre-amplifier. The pulser pulses are tagged so that after being processed by the analog-to-digital convertor, their channel address is offset and they are routed to a region of the spectrum above, and isolated from, the photon spectrum. The pulser peaks are used to accurately monitor the gain (this allows correction for any gain or zero shilis) and system resolution, which must 
have long-term stability if spectral fitting analysis techniques are to be successfully used. The pulser, with its associated software, is also capable of correcting for pulse pile-up when higher activity level samples are encountered.

The L $x$-ray spectra and the gamma-ray portions of the spectrum are analyzed separately. The higher encrgy portion is automatically analyzed in the normal fashion with a gamma-ray spectral analysis program (e.g., the VAXGAP program). The lower energy portion of the spectrum containing the $\mathrm{L} \mathrm{x}$-rays is automatically analyzed by comparing the intensities of one or more of the L x-ray peak components in the spectrum with those from a standard soil sample. The linear least-squares fitting of the L $\mathrm{x}$-ray region of the composite spectrum with its components yields accurate results. This analysis program requires little operator intervention.

The shape of the sample container permits use of a commercially available planchet automatic sample changer with modifications to accommodate the larger diameter sample container (i.e., up to $70 \mathrm{~mm}$ in diameter instead of a $50 \mathrm{~mm}$-diam planchet). The results to date indicate that measurements of $100 \mathrm{pCi} / \mathrm{g}$ of ${ }^{239} \mathrm{Pu}$ in soil can be made in a 15 minute count time with an accuracy of $<15 \%$ (one estimated standard deviation). Detection limits of $<50 \mathrm{pCi} / \mathrm{g}$ of plutonium in soil can be achieved in this count time. 


\section{CONTENTS}

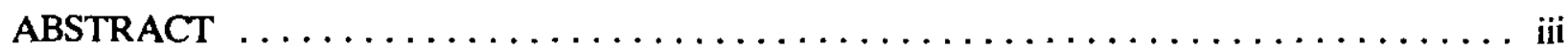

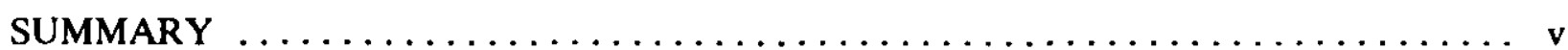

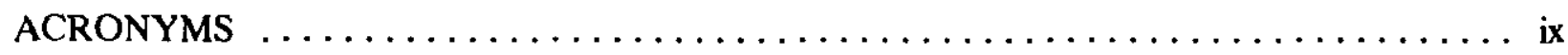

INTRODUCTION $\ldots \ldots \ldots \ldots \ldots \ldots \ldots \ldots \ldots \ldots \ldots \ldots \ldots \ldots \ldots \ldots \ldots \ldots \ldots$

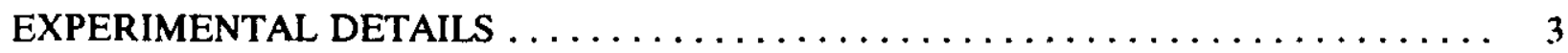

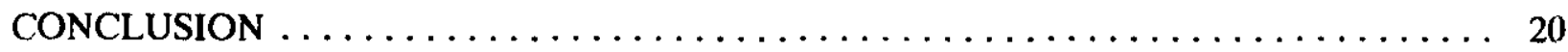

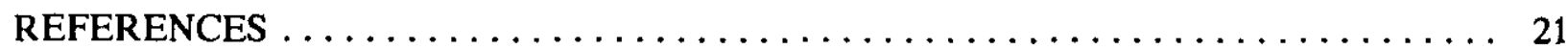

\section{FIGURES}

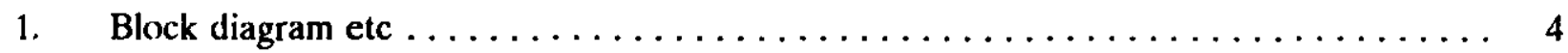

2. Hybrid pulser circuit compared to a quarter. $\ldots \ldots \ldots \ldots \ldots \ldots \ldots \ldots \ldots \ldots \ldots$

3. Multichannel analyzer spectrum with pulser pulses digitally offset so that they are stored above the gamma-ray spectrum. Gamma-ray peaks are forbidden from the region where the pulser data is stored

4. Samples containers made of ABS plastic that are used to hold the soil samples. The outside dimensions of these containers are 2.82 in. in diameter by 0.292 in.

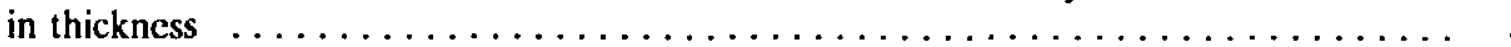

5. A measure of the nonlinearity of a 8192 channel ADC with the lincar energy function determined at two energies: 14 and $1332 \mathrm{keV} \ldots \ldots \ldots \ldots \ldots \ldots \ldots$

6. L x-ray spectrum from a highly pure plutonium standard $\ldots \ldots \ldots \ldots \ldots \ldots$

7. L $x$-ray spectrum from a highly pure americium standard $\ldots \ldots \ldots \ldots \ldots$

8. Background spectrum associated with the $\mathrm{L}$ x-ray region of the photon spectrum $\ldots \quad 14$

9. Composite spectrum of plutonium and americium L x-rays shown as open circles with the individual components of plutonium and americium shown as dots and a broken line, respectively. The background was not removed from any of the spectra. Therefore, the background component was negative and is not shown

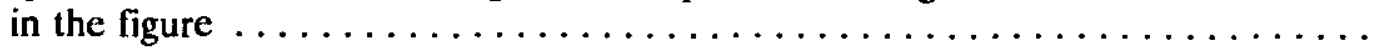

10. Calibration function determined by two measurements relating the activity to the standardization coefficient, $s_{c} \ldots \ldots \ldots \ldots \ldots \ldots \ldots \ldots \ldots \ldots \ldots \ldots \ldots$ 


\section{TABLES}

1. Mcasured ${ }^{239} \mathrm{PU}$ activity concentrations in soil matrix $\ldots \ldots \ldots \ldots \ldots \ldots \ldots$

2. Intensities for a $1800 \mathrm{~s}$ Live-Time Count of $12 \mathrm{~g}$ soil sample $\ldots \ldots \ldots \ldots \ldots \ldots$ 


\section{ACRONYMS}

ABS acrylonitrile butadiene styrene

ADC analog-to-digital

FWHM full-width-at-half-maximum

INEL Idaho National Engineering Laboratory

LANL Los Alamos National Laboratory

RML Radiation Measurements Laboratory

RWMC Radioactive Waste Management Complex

VAXGAP VAX Computer Gamma-Ray Analysis Package 


\section{Rapid Assay of Plutonium in Soils by Passive L X-Ray Counting}

\section{INTRODUCTION}

Rapid monitoring for transuranic contaminants during buried waste retrieval at the Radioactive Waste Management Complex (RWMC) of the Idaho National Engineering Laboratory (INEL) is the key to a successful campaign of buried transuranic waste retrieval. It is important to track the trend in level of loose surface contamination to assess how well the spread of contamination is controlled prior to exceeding safety and operating limits. Therefore, analysis techniques for the presence of plutonium in loose surface contamination samples (such as soils, filters, or smears) at the lowest levels of detection and the quickest time are mandatory.

The results reported herein pertain to one of the rapid monitoring methods (passive counting by $\mathrm{Ge}$ spectrometry of the $\mathrm{L}$ x-rays from the decay of plutonium and gamma rays from fission, activation, and actinide products) under consideration as described in Reference 1 . This technique may be used in conjunction with one or more of the other techniques under development at the INEL to ensure that the plutonium-contaminated waste can be retrieved in a safe and environmentally acceptable manner. Progress reports on two such techniques are given in References 2 and 3-namely, the measurement of plutonium via alpha-particle decay with a large-area ionization chamber and the on-line monitoring of air with custom solid-state constant air monitors.

Analysis for plutonium in soils by counting the $\mathrm{L} x$-rays of uranium from the alpha decay of the plutonium radioisotopes (usually ${ }^{239} \mathrm{Pu}$ ) has been proposed and previously demonstratcd. ${ }^{4-6}$ Significant progress has been made in developing this technique including the production of "optimized" sample containers and the design of a 20 -sample automated sample changer (see Reference 6). However, even with these developments and the ability to measure $<100 \mathrm{pCi}$ of ${ }^{239} \mathrm{Pu}$ per gram of soil with counting times of about one hour, wide use of this technique has not occurred.

The purpose of this particular task is to develop a local methodology for the rapid assay of plutonium in soil by $\mathbf{L}$ x-ray counting techniques. The ability to analyze smear and particulate material on air filters was reported in a previous report (see Reference 3). The efforts reported herein are intended to make this analysis technique available for routine use by employing equipment and instrumentation that is commercially available, and by developing automated calibration, counting, and analysis techniques. This paper reports the progress during FY 1991 to achieve this end.

Since the results of Trujillo, Nyhan, and Crowell were reported in 1980 (see Reference 6), several advances have occurred in Ge semiconductor detector spectrometry that are useful for this work. These include:

- Detector crystals are now routinely produced with crystal diameters of $>60 \mathrm{~mm}$ and that have energy resolutions of full-width-at-half-maximum (FWHM) of $<600 \mathrm{eV}$ at $14 \mathrm{kcV}$

- Computer interfaced, 8192 and 16,384 channel analyzers with excellent pulse-height linearities even for fixed conversion time analog-to-digital (ADC) converters are commercially available

- Precise monitoring of the spectrometer performance is now possible with advanced pulser technology 7,8 
- High-speed, low-cost, and compact laboratory computers with megabyte size memorics and large (>300 megabyte) hard disks, that can be interfaced to Ge spectrometers, are in common use

- Ge spectrometer sample changers capable of holding 100 or more planchet-type samples and operated under computer control are commercially available.

The $\mathrm{L} x$-ray and the gamma-ray portions together cover a broad energy range to be incorporated into one spectrum. Bccause of the complexity of the $\mathrm{L}$-ray spectra and their inherently different peak shapes, the $x$-rays are analyzed by a different technique than the gamma rays as discussed below. The higher-energy portion, containing the gamma rays, will be energy and efficiency calibrated in the normal fashion ${ }^{9}$ and automatically analyzed with a gamma-ray spectral analysis program, VAX computer Gamma-Ray Analysis Package (VAXGAP). ${ }^{10,11}$ This spectral analysis program is used routinely by the Radiation Measurements Laboratory (RML) at the INEL. Incorporation of the gamma-ray analysis will be performed in FY-92.

The methodology being developed applies these advances to produce an analysis system that can be operated automatically 24 hours per day in a laboratory or mobile trailer. It will provide analysis results for plutonium and americium via analysis of the $\mathrm{L} x$-ray region of the spectrum and for americium and other gamma-ray emitting radionuclides via the analysis of the gamma-ray portion of the spectrum. 


\section{EXPERIMENTAL DETAILS}

This section describes apparatus procedures and analytical methods.

Photon Spectrometer. The detector consists of a large area $(\sim 60 \mathrm{~mm}$ dia.), thin window, coaxial-type Ge detector capable of efficiently measuring photons ( $x$ and gamma rays) with energies ranging from $\sim 10 \mathrm{keV}$ to $\sim 2000 \mathrm{keV}$. This type of detector not only allows measurement of plutonium and americium activities via emitted $\mathrm{L} x$-rays and ${ }^{241} \mathrm{Am}$ via the $60-\mathrm{keV}$ gamma ray, but is also capable of efficiently detecting gamma rays from other radionuclides.

Dual-Energy Pulser. The spectrometer is being equipped (FY-92) with a dual-energy pulser (see References 7 and 8) that injects pulses into the test input of the resistive feedback prcamplifier, ${ }^{a}$ as shown in Figure 1. The pulser has been developed over a 20 year time frame by the EG\&G Idaho, Inc., Radiation Measurements Laboratory (RML) Electronics Section. The pulser, shown in Figure 2, is the latest miniaturized version. The lower- and upper-energy pulser pulses are lime tagged so that after being processed by the analog-to-digital converter their channel addresses are increased by addition of respective constants to route them to regions of the spectrum above, and isolated from, the photon spectrum, as shown in Figure 3. The positions of the pulser peaks, together with their previously measured energy equivalent, can be used to determine two parameters (a and b) of the energy-channel relationship.

$$
\mathrm{E}(\mathrm{x})=\mathrm{a}+\mathrm{bx}+\mathrm{cx^{2 }}
$$

where

$$
\begin{array}{ll}
\mathrm{E}(\mathrm{x}) & =\text { photon energy } \\
\mathrm{a}, \mathrm{b}, \text { and } \mathrm{c} & =\text { constants } \\
\mathrm{x} & =\text { channel position. }
\end{array}
$$

Similarly, the width of a peak in channel $\mathrm{x}$ is determined by the following equation:

$w(x)=w_{0}+d x$

where

$$
\begin{aligned}
& \mathbf{w}(\mathbf{x})=\text { width at channel } \mathbf{x} \\
& \mathrm{w}_{\mathrm{o}}=\text { width at channel zero } \\
& \mathrm{d}=\text { constant. }
\end{aligned}
$$

a. As of this draft, the pulser has been installed and demonstrated to meet performance requirements for a 4 microsecond amplifier time constant and a 8192 channel analyzer with the $1332-\mathrm{keV}^{60} \mathrm{Co}$ gamma ray located in channel 7800 and the pulser peaks in channel 80 and 7850 , respectively. 


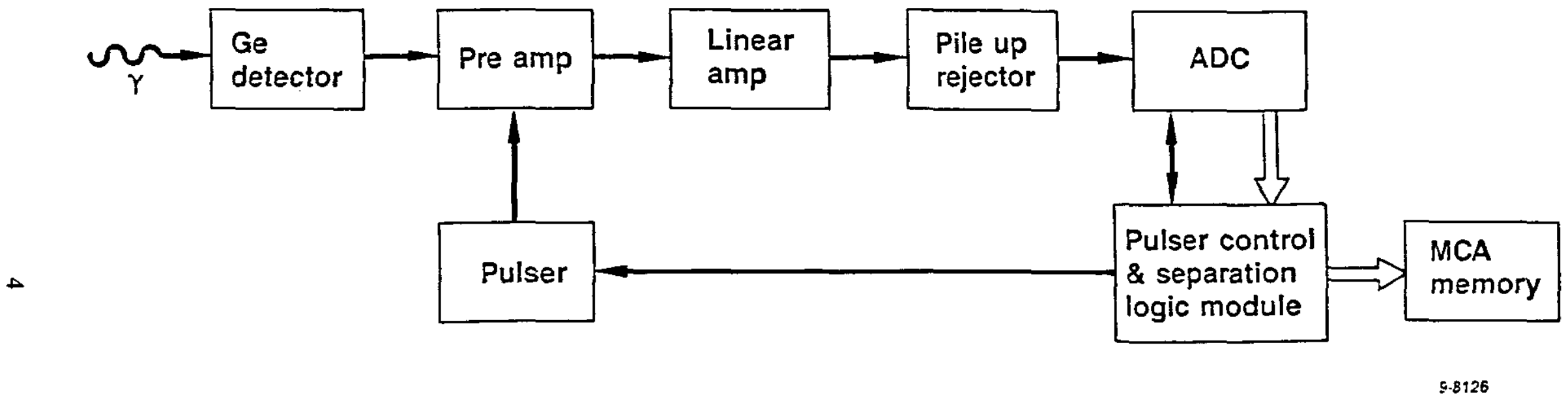

Figure 1. Block diagram of the dual-injected pulser, pulser controller, and ADC interface for subsequent removal of the pulser pulses from the photon pulse-height spectrum. 


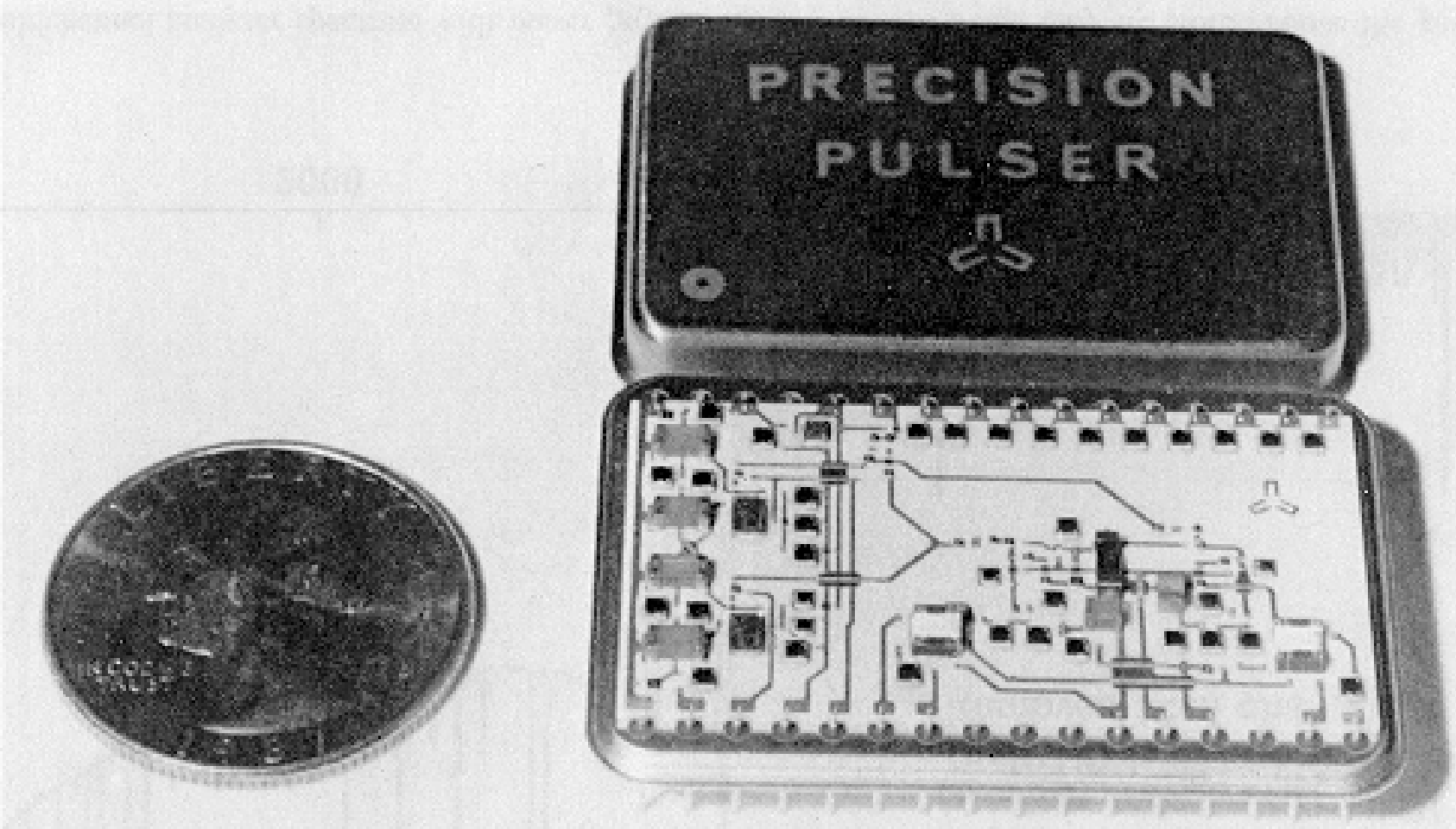

Figure 2. Hybrid pulser circuit compared to a quarter. 


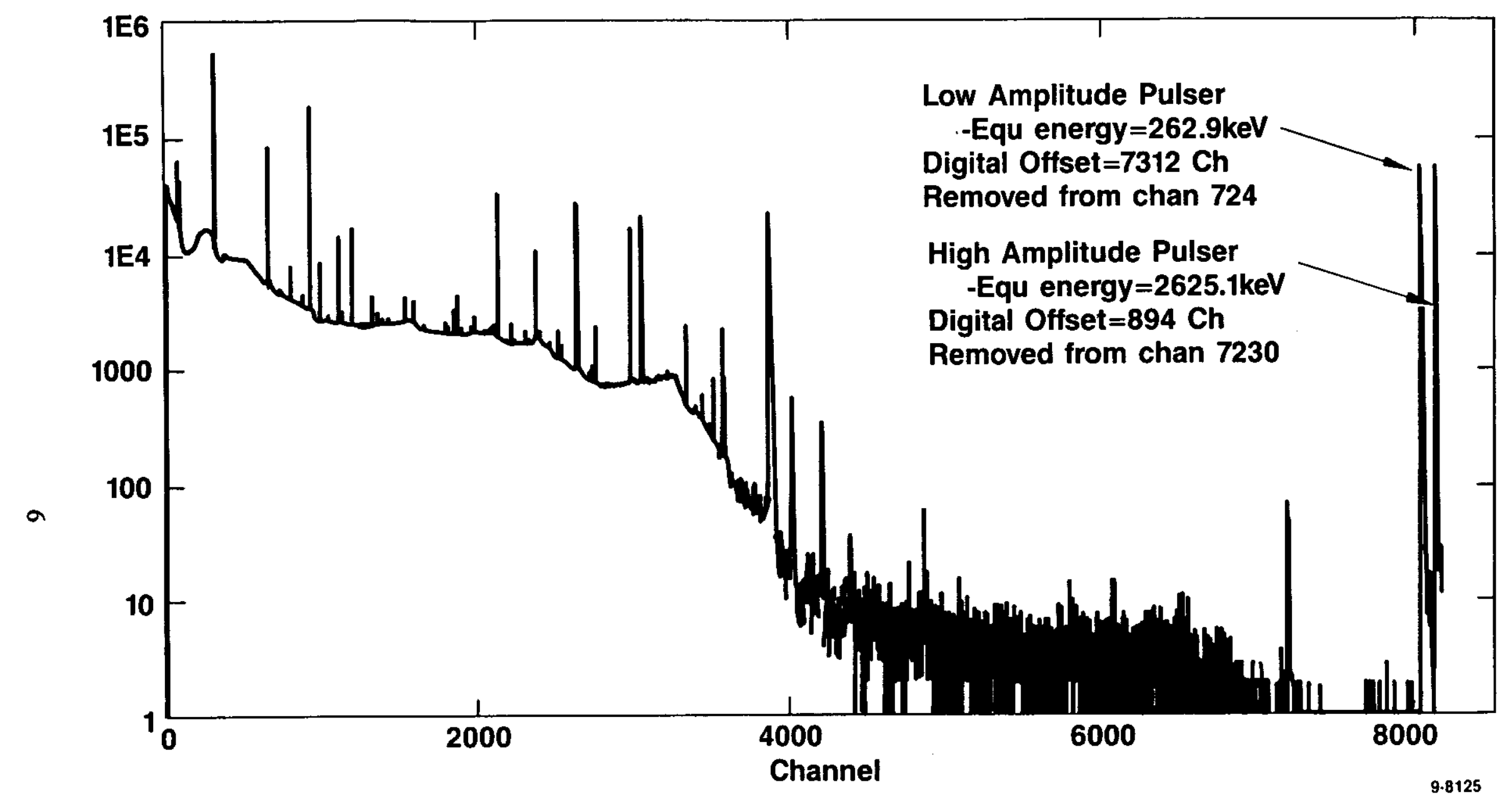

Figure 3. Multichannel analyzer spectrum with pulser puylses digitally offset so that they are stored above the gamma-ray spectrum. Gamma-ray data are forbidden from the region where the pulser data is stored. 
These parameters are determined from the calibration spectrum. Corrections in the width for sample spectra are made with the following equation:

$w(x)=\left\{\left[(W p i)^{2}-(W p c)^{2}\right]+[w o+d x]^{2}\right\}^{1 / 2}$

where

$$
\begin{aligned}
& \text { Wpi }=\text { pulser width for the sample spectrum } \\
& W_{p c}=\text { pulser width for the calibration spectrum. }
\end{aligned}
$$

The ratio of the area of a pulser peak to the number emitted by the pulser gives the correction for pulse pileup or random summing.

Sample Preparation. Soil samples were prepared by a radiochemist by sieving and/or milling dry soil to reduce the maximum particle size to less than $\sim 200$ mesh (i.e., $<0.074 \mathrm{~mm}$ ). The effects of "hot" particles within the sample is reduced by the relatively large sample (i.e., relative to typical radioanalytical sample sizes of $<1 \mathrm{~g}$ ). By use of a large area Ge detector in combination with a thin sample container, an average transmission out of the sample of $\sim 40 \%$ for uranium $L x$-rays can be achieved. In the present study, sample containers with a diameter of $65 \mathrm{~mm}$ were used; they are a few millimeters $(\mathrm{mm})$ larger in diameter than the detector crystal $(\mathrm{ca}=60 \mathrm{~mm})$. The thickness of the sample container was $3 \mathrm{~mm}$ to balance the opposing effects of the sample size and the variance in attenuation from sample to sample. The sample container chosen was designed and produced by injection molding at Los Alamos National Laboratory (LANL) by the Plastics and Composite Section originally at the request of Trujillo (see Reference 6). The sample container has a $65-\mathrm{mm}$ inside diameter, and a 5-mm inside depth as shown in Figure 4. For the present study, a spacer was made from aluminum stock ( $65 \mathrm{~mm}$ in diameter by $2 \mathrm{~mm}$ in height) so that the sample depth was limited to $3 \mathrm{~mm}$. The LANL sample container was made of acrylonitrile butadiene styrene (ABS). The lid, through which the sample is counted, is less than $1 \mathrm{~mm}$ thick. The modified sample container holds approximately 12 grams of sieved soil. The soil is loaded into a sample container by partially filling the container with soil and lightly tapping the container on a hard surface to settle it; this process is repeated until the container is full. A straight edge may be lightly drawn over the top surface of the soil prior to covering it with a lid to remove excess soil and level it. This procedure provides a reproducible method of loading the sample container and reduces the amount of settling of the soil sample inside the container over time.

Linear Least-Squares Spectral Fitting. Due to the complexity of the multiple peaks resulting from nuclei decaying by $\mathrm{L} x$-ray emission, accurate analysis of the $\mathrm{L} x$-ray region by simple peak integration or by nonlinear least-squares fitting of the peaks with a Gausian or modified Gausian is difficult. Spectra comprised of two or more sets of $L$ x-rays become exceedingly difficult to analyze for their peak areas due to the overlapping of one set of complex multiplets with another.

To overcome this, the linear least-squares spectral fitting technique, developed in the early 1950s and applied successfully to the analysis of $\mathrm{NaI}(\mathrm{Tl})$ spectra, has been applied in this present study to the analysis of the $\mathrm{L} x$-ray region of the spectra. This technique consists of measuring the spectral response of the detector for single (pure) radionuclides anticipated to be in the unknown sample. The number of components, $\mathrm{m}$, is not limited by the mathematics, but as a practical matter should not exceed about five. These response functions (spectra) can be normalized to correspond to a specific number of decays of the radionuclide. When a spectrum of an unknown sample has been acquired, these individual spectral components are combined by linear least-squares fitting to 


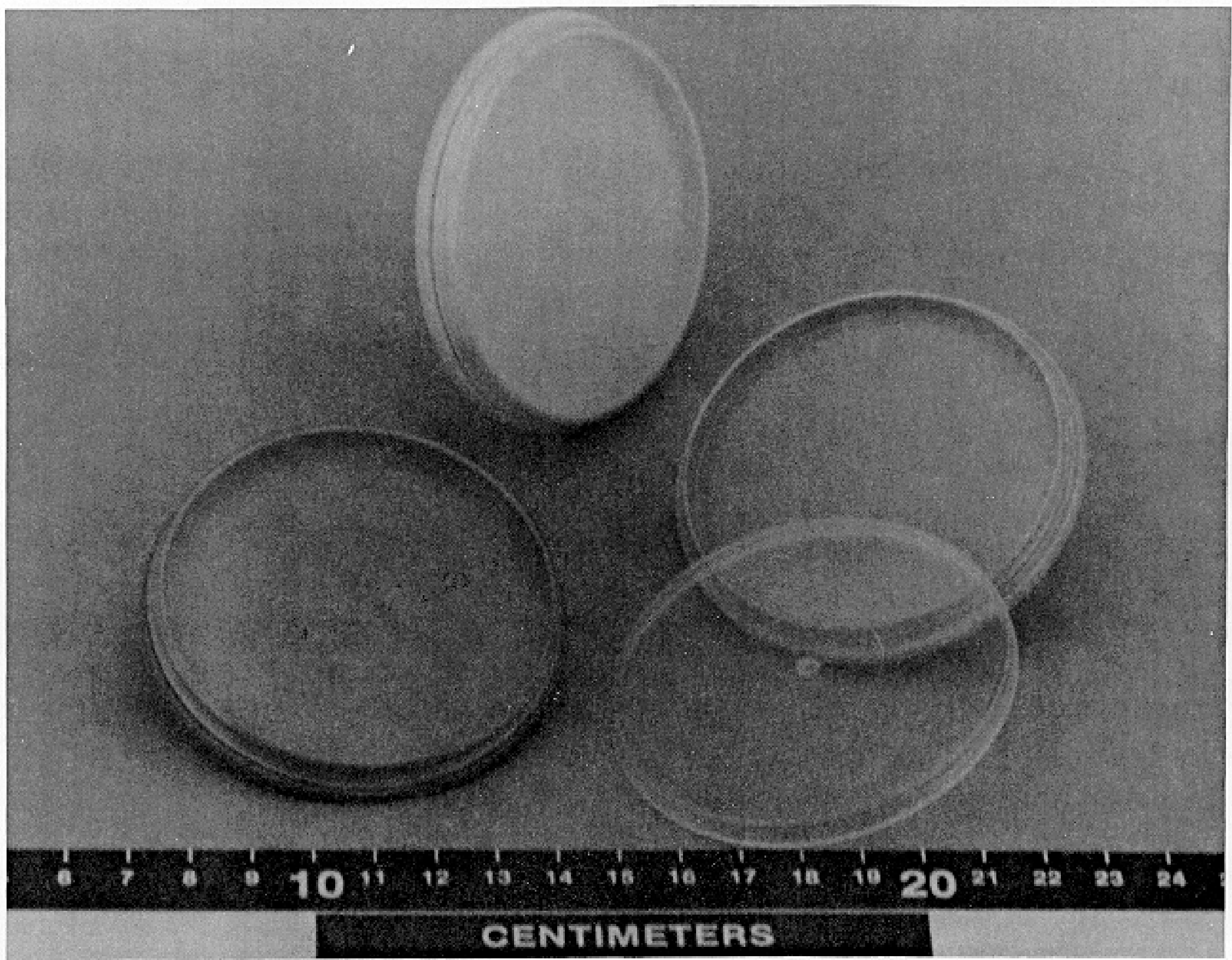

Figure 4. Samples containers made of ABS plastic that are used to hold the soil samples. The outside dimensions of these containers are 2.82 in. in diameter by 0.292 in. in thickness. 
detcrmine the contribution of each component. That is, in the following equation the standardization coefficients, $S_{j}$, are determined which minimize $R^{2}$. Here, $R_{i j}$ are the response functions and $\mathrm{N}_{\mathrm{i}}$ is the spectrum from the unknown sample.

$$
R^{2}=\sum_{i=L}^{i=u} W_{i}\left(N_{i}-\sum_{j=1}^{j=m} R_{i j} S_{j}\right)^{2}
$$

$W_{i}$ is the weighing factor for channel $i$ of the spectrum $N_{i}$ and is normally the square of the cstimated standard deviation or $1 / \mathrm{N}_{\mathrm{j}} . \mathrm{L}$ and $\mathrm{U}$ are the lower and upper channel limits over which the lincar least-squares spectral fit is performed.

At the minimum of $R^{2}$, we have $m$ equations of the form:

$\mathrm{dR}^{2} / \mathrm{dS}_{\mathrm{j}}=0$

where

$$
\mathrm{j}=1, \mathrm{~m} \text {. }
$$

The information regarding the contribution of each component is contained in the energy region between about 10 and $30 \mathrm{keV}$; only this portion of the unknown spectrum is fitted by linear lcast squares. In this way, the sensitivity and accuracy of the fit is optimized. Further, since an uncertainty is deduced for each standardization coefficient, $S_{j}$, and a reduced chi-square is reported for the fit, the quality of the overall fit can be easily assessed. If the quality of fit is poor, the fit can be redone with more or fewer component spectra, with a different set of calibration spectra (component spectra) that better represent the sample matrix, or with the response spectra after gain or zero shifting the unknown spectrum.

Measurement of the Pulse-Height-Nonlinearity of the ADC. Identification of radionuclide activities is dependent on accurate energy measurement; this usually requires the measured energies to lic within $0.5 \mathrm{keV}$ of the library values. This level of accuracy is achicvable by most present day analog-to-digital converters for energy ranges between $\sim 80 \mathrm{kcV}$ and $3000 \mathrm{keV}$; however, below $80 \mathrm{kcV}$ this is often not the case. Accurate spectral-fitting, as used in the x-ray analysis, also requires that all spectra involved in the fitting process be at or adjusted to be at the same gain. Therefore, the deviation from pulse-height linearity of the ADC over a range of channels corresponding to $14 \mathrm{keV}$ to $1332 \mathrm{keV}$ was measured as well as the gain and zero stability of the spectrometer. 
Measurements with two types of analog-to-digital converters revealed excellent results. ${ }^{\text {a }}$ As shown in Figure 5, a two-point energy calibration with the $14-\mathrm{keV}$ peak of ${ }^{57} \mathrm{Co}$ in channel 98 and the $1332-\mathrm{keV}$ peak of ${ }^{60} \mathrm{Co}$ in channel 7658 is able to measure the energy of a peak with a linear energy function to within $0.3 \mathrm{keV}$ over this entire range. This peak position measurement accuracy demonstrates the quality of the pulse-height linearity of today's ADC's and, coupled with the dualenergy pulser, the capability to provide accurate energy measurements for all photons of interest. The stability of the gain and zero of the energy scale over a week period of time indicated that the gain deviated only in the fourth place and that the zero shifted over time by about two tenths of a channel. An energy scale up to $1332 \mathrm{keV}$ is sufficient since essentially all anticipated gamma-ray emitting radionuclides present in aged $(>10 \mathrm{y})$ buried waste have gamma rays with energies below $1332 \mathrm{keV}$.

Measurement of L $x$-Ray Response Spectra. Measurement of the $\mathrm{L} x$-ray response spectra for plutonium and americium involved the preparation of a set of three samples of clean soil having a consistent composition and simulating the composition of the unknown samples to be analyzed. (If different types of soil samples (density, elemental, or $\mathrm{Pu}$ isotopic composition) are anticipated, additional sets of response spectra shall be obtained.] The three calibration samples within each set consisted of an unspiked sample, a sample spiked uniformly with a known activity of high purity ${ }^{239} \mathrm{Pu}(\sim 1000 \mathrm{pCi} / \mathrm{g})$, and one spiked with a known activity of high purity ${ }^{241} \mathrm{Am}(\sim 1000 \mathrm{pCi} / \mathrm{g})$. After installation of the spectrometer, individual spectra of each calibration standard from each set were acquired for a known time $(\sim 10,000$ seconds $)$ and at the same energy scale. These spectra provided spectral shapes and intensities for the background spectrum (i.e., for unspiked samples) and for known amounts of each radionuclide present as shown in Figures 6-8. Sufficient statistics in each calibration spectrum were acquired so that the associated statistical uncertainty can be considered negligible relative to the statistical uncertainty of the "unknown" sample spectra. Because the spectrometer was very stable and all response spectra were taken sequentially, the gain and zero of each spectrum were essentially the same. However, once the dual-energy pulser is installed, the energy scale for each spectrum will be measured by the dual-energy pulser and the energy scales can be adjusted prior to analysis, if necessary, to make them all the same.

$L x$-Ray Calibration for Plutonium and Americium. After establishing a file of response spectra (i.c., ${ }^{239} \mathrm{Pu},{ }^{241} \mathrm{Am}$, and background), a calibration curve was measured. Spectra of other "mixed" standards containing known activities over the range of interest for ${ }^{239} \mathrm{Pu}$ ( ${ }^{241} \mathrm{Am}$ also is in samples) were acquired for known times and at the same energy scale as used to acquire the response spectra. A linear-least-squares fit of the "mixed" standards with the respective set of calibration spectra measured above yielded activity for each radionuclide as a function of standardization coefficients, $\mathrm{S}_{\mathrm{j}}$, as shown in Equation (6).

a. A Canberra model No. 8076 Wilkinson-type ADC and a Nuclear Data model No. ND581 fixed conversion time ADC were used in these measurements. 


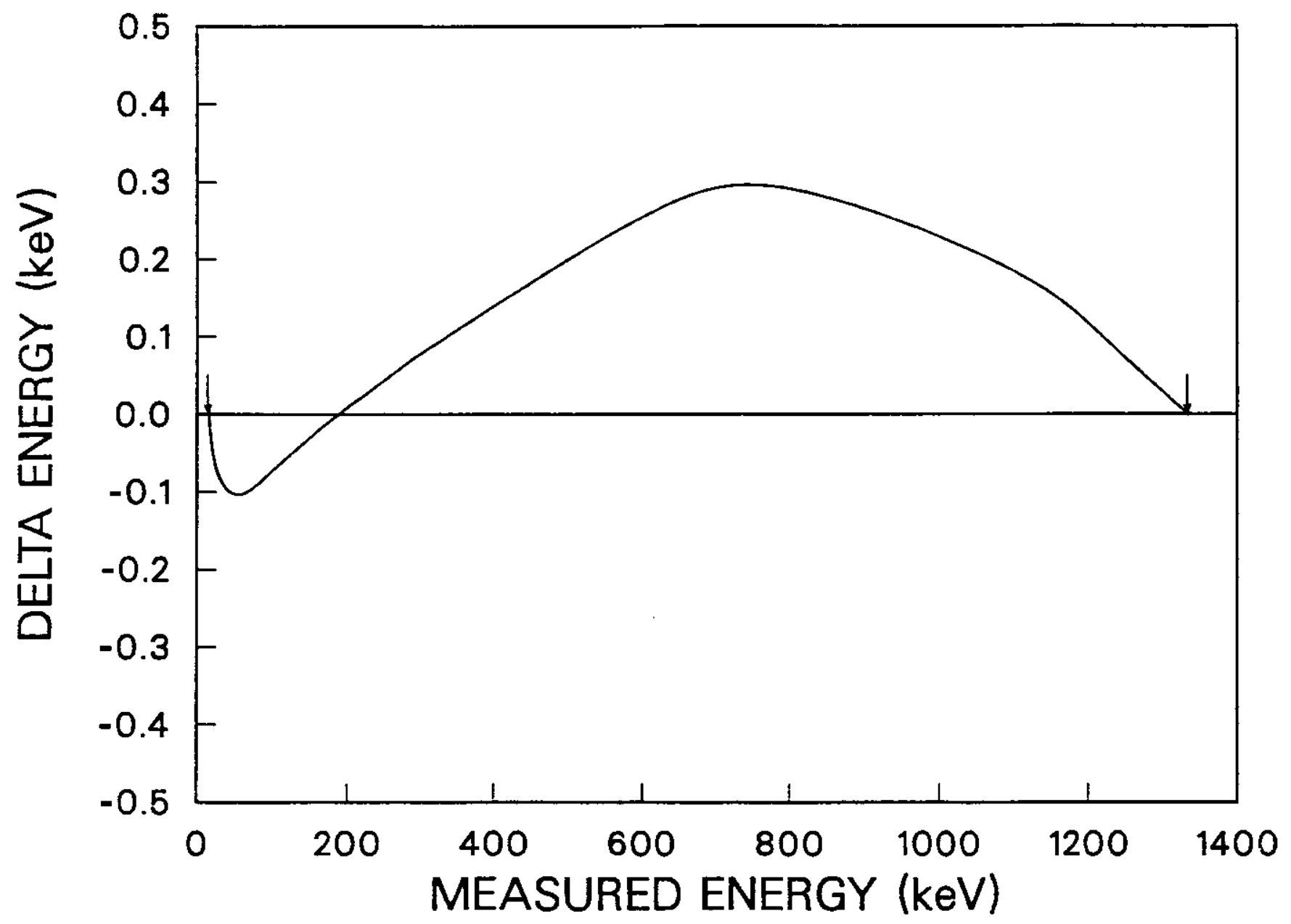

Figure 5. A measure of the nonlinearity of a 8192 channel ADC with the linear energy function determined at two energies: 14 and $1332 \mathrm{keV}$. 
11.14 GRAMS OF SOIL

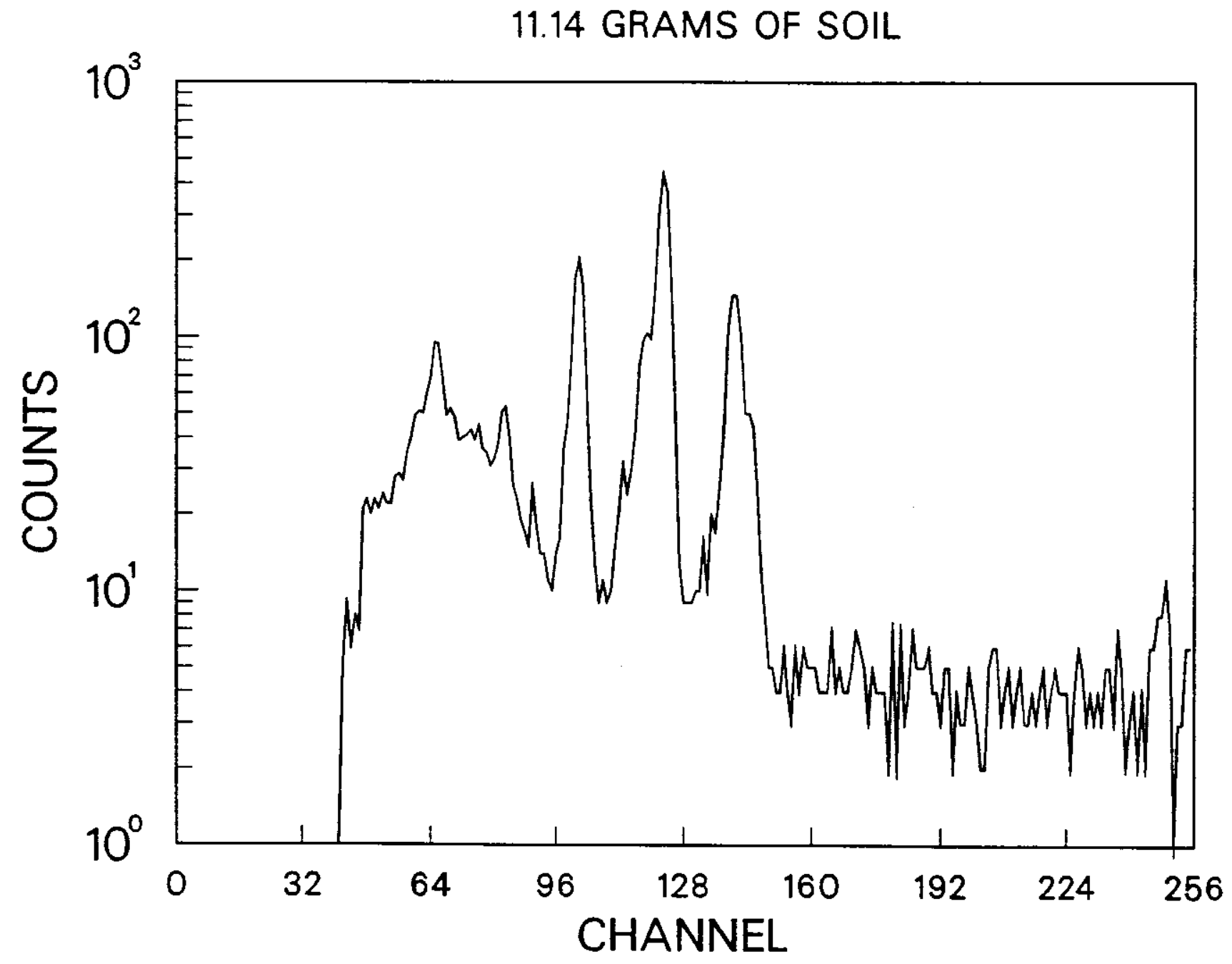

Figure 6. L x-ray spectrum from a highly pure plutonium standard. 


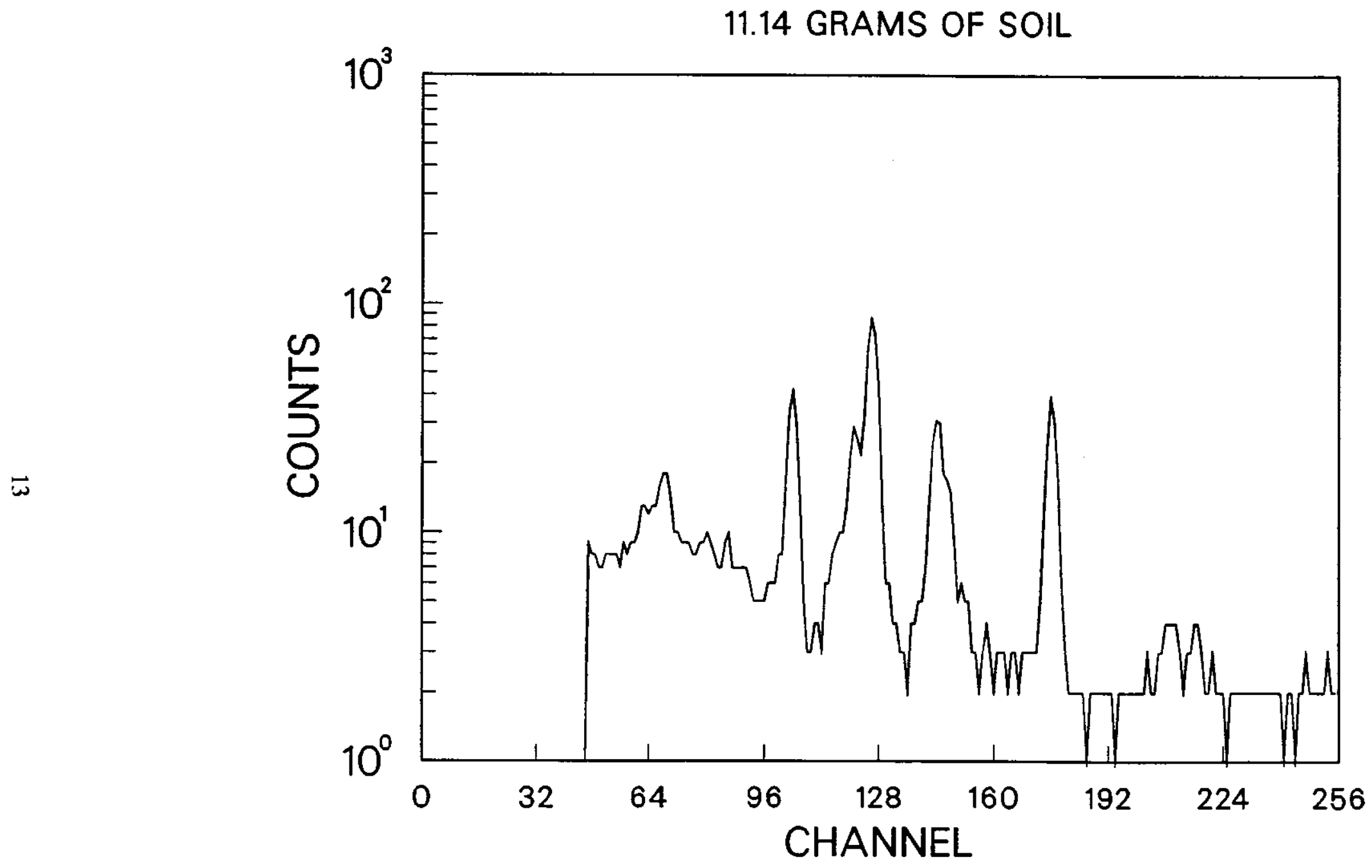

Figure 7. L $\mathrm{x}$-ray spectrum from a highly pure americium standard. 
11.14 GRAMS OF SOIL

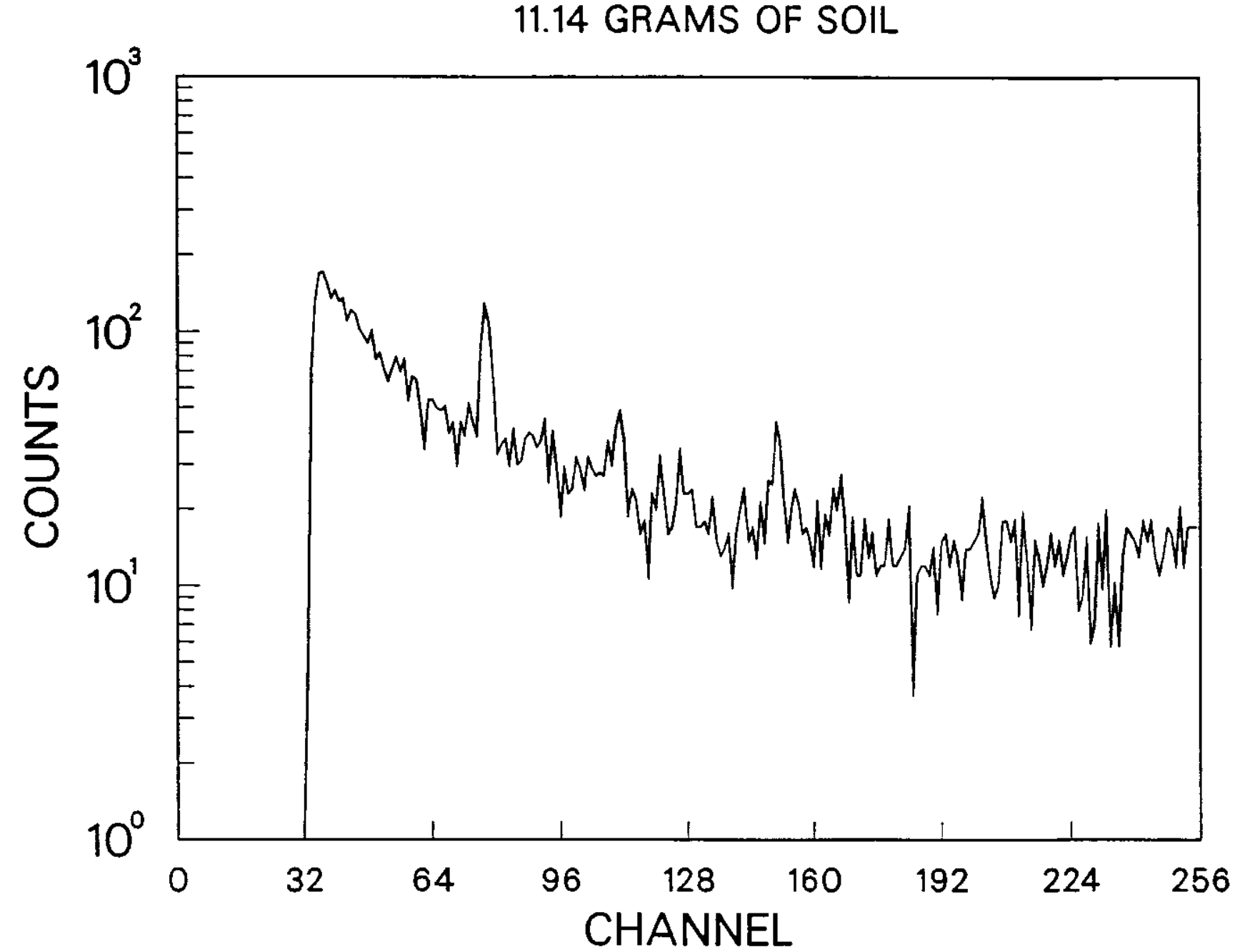

Figure 8. Background spectrum associated with the L $\mathrm{x}$-ray region of the photon spectrum. 
where

$F_{j}=$ the standardization factor

$A_{j}=$ the activity of radionuclide $j$

$A_{\delta}=$ the activity or normalized activity of the response spectrum.

If the response spectra are normalized to a specific activity, then $F_{j}$ simply normalizes for different counting times.

Figure 9 shows a spectrum from a "mixed" standard of plutonium in soil with the least-squares fit results overlayed. The reduced chi-square is a measure of the quality of the least-squares spectral fit and should lie near 1.0. A calibration curve from two "mixed" standards is shown in Figure 10.

Sample Acquisition and Analysis. Samples, that were treated as unknown amounts of plutonium, americium, and other gamma-ray emitting radionuclides, were prepared and counted in the same manner as the response and "mixed" standards but were counted for shorter times. The spectra were fitted with the response spectra in the same manner as with the "mixed" standard except the measured standardization coefficient, $\mathrm{Sj}$, was related to activity through the normalization factor, $F_{j}$, as shown in Equations (5) and (6) and Figure 10. If a poor fit is encountered and the reduced chi-square is greater than 2 , the source of a poor fit should be investigated. In some cases, as indicated above, a new calibration source set may need to be prepared if the unknown sample matrix is different than that of the existing calibration set.

In order to determine the accuracy achievable with this method, "mixed" standards of plutonium containing $103 \mathrm{pCi} / \mathrm{g}$ and a smaller amount of ${ }^{241} \mathrm{Am}$ were prepared, counted, and analyzed as if they were samples. The results from $900 \mathrm{~s}$ and $1800 \mathrm{~s}$ counts are presented in Table 1. Note that plutonium activity levels as low as $103 \mathrm{pCi} / \mathrm{g}$ can be measured in the presence of $4 \mathrm{pCi}$ of ${ }^{241} \mathrm{Am}$ per gram of soil to an accuracy of $<15 \%$ in a 900 second count.

Table 1. Measured ${ }^{239} \mathrm{Pu}$ activity concentrations in soil matrix.

\begin{tabular}{cccc}
\hline & \multicolumn{2}{c}{ Activity Concentration (pCi/g) } & \\
\cline { 2 - 3 } $\begin{array}{c}\text { Count time } \\
\text { (seconds) }\end{array}$ & Actual & Measured & $\begin{array}{c}\text { Projected LLD } \\
(\mathrm{pCi} / \mathrm{g})\end{array}$ \\
\hline 900 & $103.0 \pm 1.4$ & $111 \pm 14(13 \%)$ & 42 \\
1800 & $103.0 \pm 1.4$ & $98 \pm 11(12 \%)$ & 33 \\
\hline
\end{tabular}




\subsection{GRAMS OF SOIL}

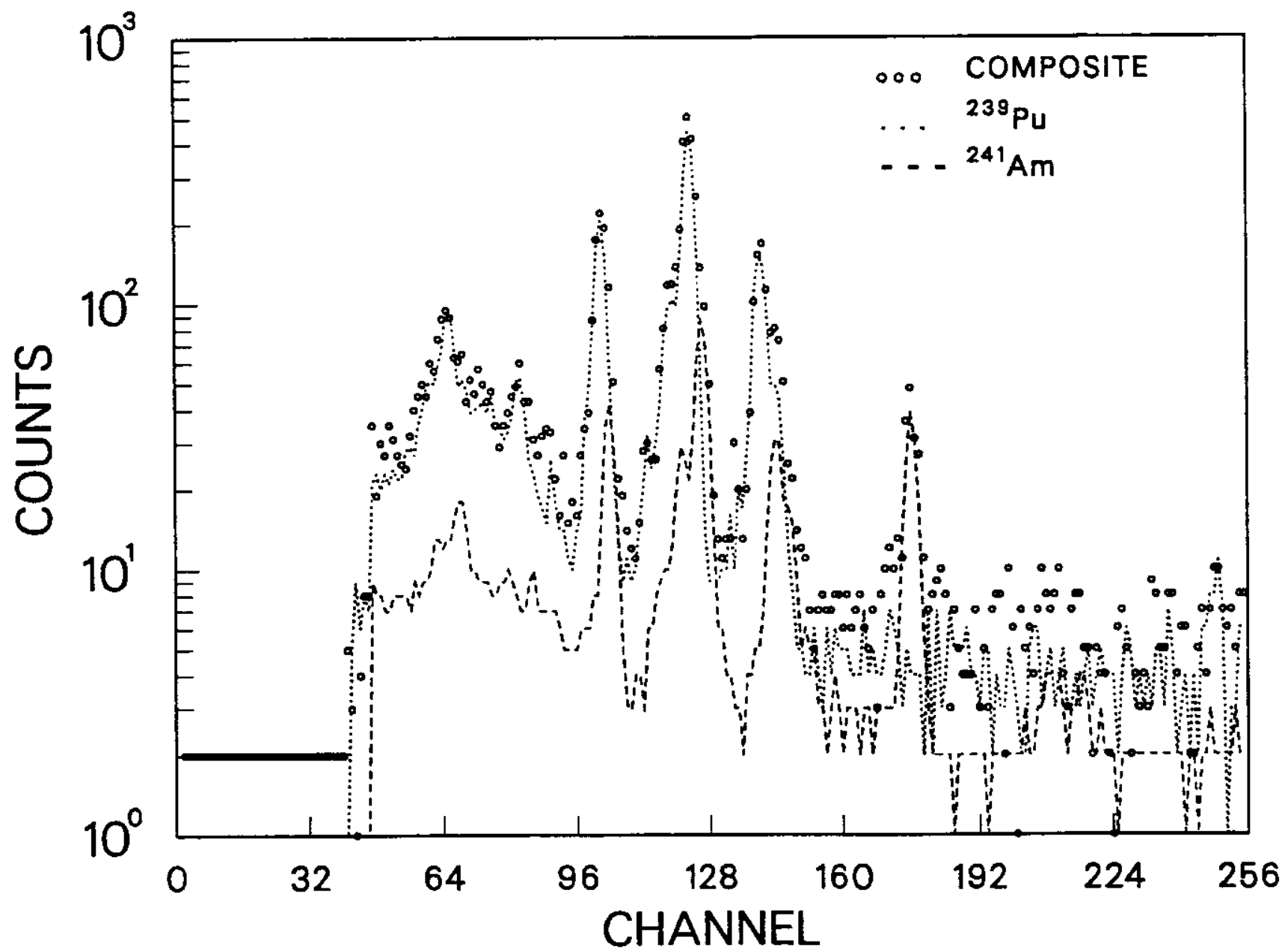

Figure 9. Composite spectrum of plutonium and americium $\mathrm{L}$-rays shown as open circles with the individual components of plutonium and americium shown as dots and a broken line, respectively. The background was not removed from the component or composite spectra. Therefore, in the least-sqaures fitting process the background component was negative and is not shown in the figure. 


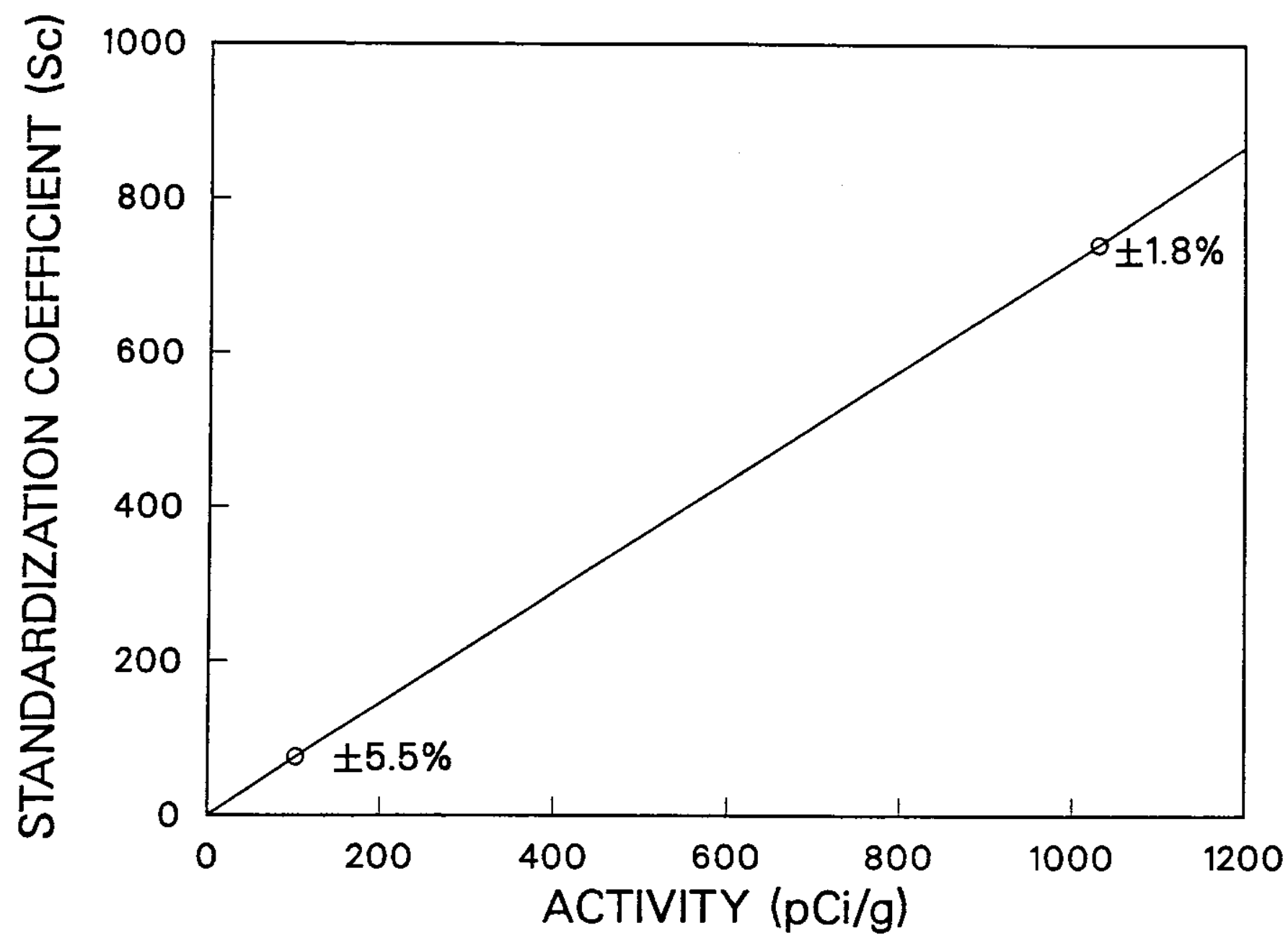

Figure 10. Calibration function determined by two measurements relating the activity to the standardization coefficient, $\mathrm{S}_{\mathrm{c}}$. 
Detection Limits and Quality Assurance. The method outlined by L. A. Currie ${ }^{12}$ for the determination of detection limits (also lower limits of detection) that meet specific statistical criteria is in wide use and is recommended here. However, since several radionuclides and their associated spectral components overlap and contribute to a sample spectrum (see Figure 9), none of the regions of interest are free of interferences. Therefore, in this application the detection limits for plutonium and americium in soil are most easily determined by relating them to the estimated standard deviation in the measured activity.

When the number of counts in the energy region of interest of the background spectrum is greater than about 42 counts (over 50 counts are in the energy region of interest in background spectrum for a $900 \mathrm{~s}$ count time), simple "working" expressions may be stated for the detection limit (as defined by Currie). When the uncertainty in the standardization coefficient, which relates the amount of a component present to the activity, is $\left(\sigma_{b} / S\right) 100+30.4 \%\left(\sigma_{b}\right.$ is the standard deviation of the blank and $S$ is the net signal), the amount of component present is considered to be at the detection limit, $\mathrm{L}_{D}$. The $\mathrm{L}_{D}$ values as reported in Table 1 have been deduced based upon measured activities and associated uncertainties for real samples whose activities are within a lactor of two or three of the deduced detection limit.

Onc advantage that the dual-energy pulser will provide is an accurate energy calibration for all spectra. This energy calibration is especially valuable for those spectra associated with radionuclides emitting only one photon or with all photons grouped within a small energy range. As a result, all linear least-squares fitting can be performed at essentially the same energy scale since the $x$-ray spectra can be shifted to that scale. The pulser not only will provide an energy calibration it also will provide a measure of the detector resolution. If a detector begins to deteriorate or noise enters the system, it is observed in the pulser peaks. Further, correction for pulse pilc-up, although not anticipated when counting environmental level samples, can be automatically applied from information in the pulser peaks. These features of the pulser will provide excellent quality control for data acquired by this spectrometer system.

Information on the quality of the results from the linear least-squares fit is provided by the reduced chi-square and the channel-by-channel residuals that are provided. Table 2 is a printout showing the raw standardization coefficients and the reduced chi-square value resulting from a lit. The reduced chi-square value of 1.26 indicates that the correct spectral components were used in the fit, that the energy scale was satisfactory, and that sample matrices were similar. In cases where the reduced chi-square value is large, a printout of the channel-by-channel residuals between the 1 sample spectrum and the sum of the component spectra allows the operator to identify spectral regions in which the fit is poor and address the cause. All of the above analysis features contribute to ensuring the quality of the least-squares spectral fitting process and the resulting measured activities. 
Table 2. Intensities for a $1800 \mathrm{~s}$ Live-Time Count of $12 \mathrm{~g}$ soil sample.

\begin{tabular}{lccccc}
\hline Spectrum & $\mathrm{S}_{\mathrm{j}}$ & $\begin{array}{c}\text { Std. } \\
\text { deviation }\end{array}$ & Nuclide & $\begin{array}{c}\text { Activity } \\
(\mathrm{pCi} / \mathrm{g} \text { of soil) }\end{array}$ & $\begin{array}{c}\text { Detection limit } \\
(\mathrm{pCi} / \mathrm{g} \text { of soil) }\end{array}$ \\
\hline Composite & & & & & \\
Standard & 0.00267882 & 0.00068745 & ${ }^{241} \mathrm{Am}$ & $3.97 \pm 26 \%$ & 32.2 \\
Standard & 0.01349531 & 0.00155421 & ${ }^{239} \mathrm{Pu}$ & $98.5 \pm 12 \%$ & \\
Standard & $\mathbf{0 . 0 7 4 4 6 8 9 0}$ & $\mathbf{0 . 0 0 9 7 8 7 6 5}$ & & & \\
Degrees of freedom $=97$ & Quality of FIT number $=1.259$ & The Sum Sq. Res. $=122.11$ \\
\hline
\end{tabular}




\section{CONCLUSION}

The measurement of plutonium using $\mathbf{L} x$-ray measurements is a promising technique to assess the spread of contamination during buried waste retrieval. The $\mathbf{L} x$-ray measurement technique avoids using the costly and time consuming radiochemistry techniques that take hours to perform and allows the entire radioanalysis of alpha- and gamma-emitting radionuclides in one count in a ficld-deployable setting.

The technique presented herein has been demonstrated to have the capability to analyze $-12 \mathrm{~g}$ soil samples contaminated by plutonium down to $50 \mathrm{pCi} / \mathrm{g}$ for count times as short as 15 minutes. Spectral fitting of the sample spectra with response spectra permit this process to be performed automatically with built-in quality assurance checks. The future addition of a dual-encrgy pulser will also provide quality assurance checks by accurately measuring the energy scale for every spectrum even when no photon peaks are in the spectrum (e.g., some background spectra). Analysis of gamma-ray emitting radionuclides can be achieved by the use of a gamma-ray spectral analysis package on the upper portion of the same photon spectrum as accumulated for the $L \mathrm{x}$-ray spectrum. We believe that this technique can be expanded to the analysis of a varicty of other $\mathrm{x}$-ray emitting radionuclides (e.g., flux monitors), samples contained on filter paper (e.g., particulate material on air filters), and from different waste forms (e.g., glass). With modifications, this system can be incorporated into a portable, battery-powered, in-field instrument. 


\section{REFERENCES}

1. C. W. Sill and R. J. Gehrke, Test Plan for Rapid Transuranic Monitoring of Soil and Air Dusts By Direct Large-Area Alpha Spectrometry and L-Shell X-Ray Spectrometry, EGG-WTD-9735, May 1991.

2. C. W. Sill, Rapid Monitoring of Soil, Smears, and Air Dusts by Direct Large-Area Alpha Spectrometry, EGG-WTD-10080, January 1992.

3. C. V. McIsaac, C. W. Sill, R. J. Gehrke, P. G. Shaw, P. D. Randolph, C. R. Amaro, P. J. Pawelko, D. N. Thompson and G. G. Loomis, Rapid Monitoring for Transuranic Contaminants During Buried Waste Retrieval, EGG-WTD-9412, March 1991.

4. I. S. Sherman, M. G. Strauss, and R. H. Pehl, "IEEE Transactions on Nuclear Science," NS-27, 1980, p. 695.

5. L. West, C. J. Umbarger, and T. Dempsey, U.S. DOE Report LA-UR-78-87, 1978.

6. G. Trujillo, J. W. Nyhan, and J. M. Crowell, U.S. DOE Report LA-8376-LLWM, 1980.

7. L. O. Johnson, E. W. Killian, R. G. Helmer, and R. Coates, "IEEE Transactions on Nuclear Science," NS-28, 1981, p. 638.

8. J. K. Hartwell and S. G. Goodwin, "IEEE Transactions on Nuclear Science," NS-36, 1989, p. 615 .

9. Calibration and Use of Germanium Spectrometers for the Measurement of Gamma-Ray Emission Rates of Radionuclides, ANSI N42.14-1991, Institute of Electrical and Electronics Enginecrs, Inc., 345 East 47 St., New York, NY 10017-2394, USA.

10. E. W. Killian and J. K. Hartwell, VAXGAP: A Code for the Routine Analysis of Gamma-Ray Pulse-Height Spectra on a VAX Computer, EGG-2533, May 1988.

11. E. W. Killian and D. A. Femec, Operator's Guide for the Gamma Ray Analysis Package VAXGAP, EGG-2672, June 1992.

12. L. A. Currie, "Analytical Chemistry," 40, 1968, p. 586. 